\title{
Acromegaly gigantism with dilated cardiomyopathy and heart thrombus
}

Farida Chentli, Amina Laloui, Dia-Eddine Boudiaf, Said Azzoug

Department of Endocrinology and Metabolism, Bab El Oued Teaching Hospital, Algiers, Algeria.

Introduction:

Dilated cardiomyopathy with congestive heart failure (CHF) is an exceptional complication of growth hormone excess. It occurs in nearly $3 \%$ of acromegaly with or without gigantism. Our aim was to report a case with $\mathrm{CHF}$, large right atrial thrombus, and pulmonary embolism

Case report: A 41 year-old man, known as having an acromegaly-gigantism due to a large pituitary somatotroph adenoma. That one was operated on twice, but the tumor persisted and $\mathrm{GH}=79 \mathrm{ng} / \mathrm{ml}$. As somatostatin analogues were not available, radiotherapy was proposed but was refused by the patient, then he was lost in sight for 13 years. He consulted again in 2015 for heart failure. Heart echosonography showed a dilated cardiomyopathy with severe left ventricular dysfunction (ejection fraction $=25 \%$, shortening fraction= $15 \%$ ) and a right atrial thrombus (Figure1)

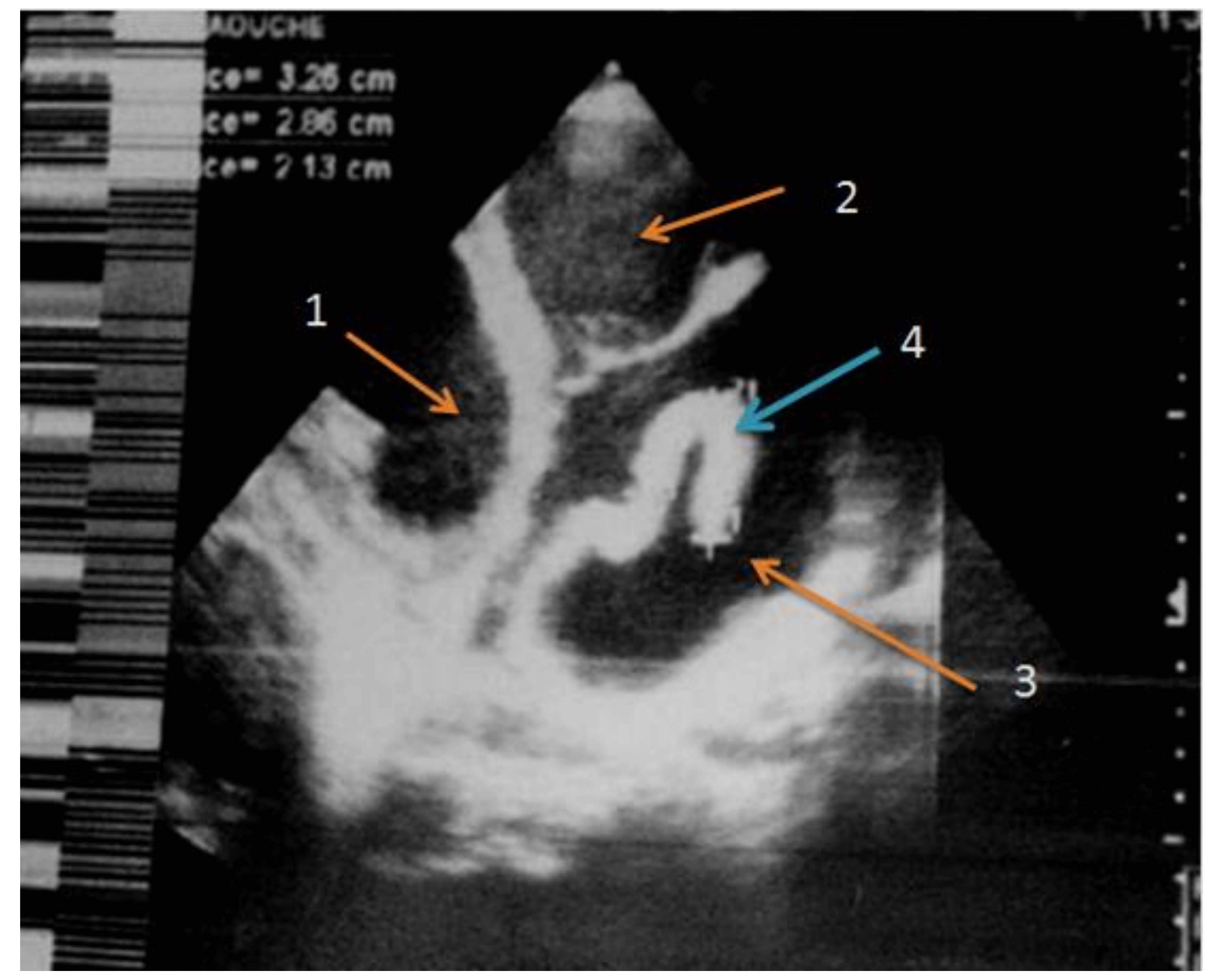

Figure 1: Left ventricule (1), right ventricule (2), right atrium (3), thrombus (4).

The patient was admitted in intensive care unit, but he died of pulmonary embolism.

CONCLUSION: Although very rare, heart complication due to $\mathrm{GH}$ excess can be fatal even in young people as in our case. Therefore, it is mandatory to treat aggressively patients with acromegaly on due time. 